\title{
Evre 2 kolon tümörlerinde klinikopatolojk faktörlerin sağkalımla ilişkisi
}

\section{Relationship between clinicopathological factors and prognosis in stage 2 colon cancer}

\section{(D) Salih KILIÇ ${ }^{1}$ (D) Dinçer AYDIN²}

Batman Bölge Devlet Hastanesi, ${ }^{1}$ Gastroenteroloji Kliniği, Batman

Derince Devlet Hastanesi, ${ }^{2}$ Onkoloji Kliniği, Derince, Kocaeli

Giriş ve Amaç: Kolorektal kanserler tüm dünyada ve ülkemizde sindirim sistemi kanserlerinin başında gelmektedir. Kolorektal kanserlerin prognozunu etkileyen ve tedavide değişikliğe yol açan birçok prognostik faktör bulunmaktadır. Bu prognostik faktörler hem genel sağkalımı hem de hastalıksız sağkalımı etkilediği gibi bazıları tedavinin takibinde de kullanılabilmektedir. Calışmamızda kolorektal kanserin prognozunu etkileyen klinikopatolojik faktörlerin genel ve hastalıksız sağ kalım üzerine olan etkilerinin gösterilmesi planlanmıștır. Gereç ve Yöntem: Ocak 2000-Aralık 2014 arasında Kartal Dr. Lütfi Kırdar Eğitim ve Araştırma Hastanesi Tıbbi Onkoloji Polikliniğine bașvuran ardıșık 277 evre 2 kolorektal kanserli hasta çalıșmaya alınmıștır. Hastalar histopatolojik verilerine göre değerlendirilmiş ve poliklinik ve patolojik kayıtları incelenerek hastalıksız sağ kalım ve genel sağ kalım süreleri belirlenmiştir. Bulgular: Çalışmaya 159 (\%57.4) erkek 118 (\%42.6) kadın olmak üzere toplam 277 kişi dahil edildi. Hastaların medyan yaşı 60 (aralık 28-89) idi. 277 hastanın medyan sağkalım süresi 21 (aralık 1-184) aydı. Sonuç: Perinöral invazyon ve tanı anındaki T evresinin genel sağkalım üzerine istatistiksel etkisi olduğu izlenirken; lenfovasküler invazyon, perinörel invazyon, T evresi, tümör yerleşimi ve obstrüksiyon varlı̆̆ının hastalıksız sağkalım üzerine istatistiksel etkisi olduğu görüldü.

Anahtar kelimeler: Evre 2 kolon tümörleri, genel sağkalım, hastalıksız sağkalım

\section{GİRİs}

Kolorektal kanserler tüm dünyada ve ülkemizde sindirim sistemi kanserlerinin başında gelmektedir. Küresel olarak bakıldığında kolorektal kanser erkeklerde 2. kadınlarda ise 3. en sık tanı konulan kanser olma özelliğini taşımaktadır. Ylllık yaklaşık olarak 132700 yeni kalın barsak kanseri tanısı konulmakta, bunun 93090 kadarının kolon kanseri ve geri kalanının ise rektal kanserler olduğu görülmektedir (1). Tedavideki tüm gelişmeler ve erken tanı ve tedavi metodlarına rağmen hastaların 5 yıllık sağkalımları halen istenilen düzeylerde değildir. Hastaların yaklaşık \%60 kadarn 5 yll içinde hayatını kolorektal kanser ve komplikasyonlarına bağlı olarak kaybetmektedir.

Kolorektal kanserlerin prognozunu etkileyen ve tedavide değişikliğe yol açan birçok prognostik faktör bulunmaktadır. Bu prognostik faktörler hem genel sağkalımı hem de hastalıksız sağkalımı etkilediği gibi bazıları tedavinin takibinde de kullanılabilmektedir.

Biz de çalışmamızda kolorektal kanserin prognozunu etkileyen klinikopatolojik faktörlerin [cinsiyet, tümör çapı, evre,
Background and Aims: Colorectal cancer is the leading cancer of the digestive system affecting people worldwide. There are several prognostic factors that influence the prognosis of colorectal cancers and demonstrate changes with treatment. These prognostic factors affect both the overall and disease-free survival, some of which can be applied in the treatment follow-up. Here, we investigated the effects of clinicopathological factors on the overall and disease-free survival of patients that affected the prognosis of colorectal cancer. Material and Methods: We included 277 consecutive patients with stage 2 colorectal cancer admitted to the Kartal Dr. Lütfi Kirdar Training and Research Hospital Medical Oncology Outpatient Clinic between January 2000 and December 2014. The study patients were evaluated according to their histopathological data, and their disease-free and overall survival periods were determined by examining the outpatient and pathological medical records. Results: Of the 277 study subjects, 159 (57.4\%) were men and 118 (42.6\%) were women of a median age 60 years (age range: $28-89$ years). The median survival time of the patients was 21 (range: 1-184) months. Conclusion: We observed that the T-stage at the time of diagnosis and perineural invasion had a statistical effect on the overall survival and that lymphovascular invasion, peripheral invasion, T-stage, tumor placement, and obstruction trait had statistical effects on the disease-free survival.

Key words: Stage 2 colon tumors, overall survival, disease-free survival

lenfovasküler invazyon (LVI) ve perinöral invazyon (PNI), obstrüksiyon, perforasyon, tümör yerleşimi, lenf nodu sayısı, histopatoloji, hasta performansı, adjuvan kemoterapi duru$\mathrm{mu}$ ] genel ve hastalıksız sağkalım üzerine olan etkilerini araştırmayı planladık.

\section{GEREC ve YÖNTEM}

Ocak 2000- Aralık 2014 arasında Kartal Dr. Lütfi Kırdar Eğitim ve Araştırma Hastanesi Tibbi Onkoloji Polikliniğine başvuran ardışık 277 evre 2 kolorektal kanserli hasta Helsinki Deklerasyonu kararlarına, hasta hakları yönetmeliğine ve etik kurallara uygun olarak ve Dr. Lütfi Kırdar Kartal Eğitim ve Araştırma Hastanesi Etik Kurulundan 89513307/1009/472 dosya numarası ile 23.07.2015 tarihinde onay alınarak çalışmamızda değerlendirildi. Hastalar histopatolojik verilerine göre değerlendirildi. Hastaların poliklinik ve patolojik kayıtları incelenerek hastalıksız sağkalım ve genel sağkalım süreleri belirlendi. Hastalıksız sağkalım süresi, tanı tarihinden itibaren lokal nüks veya uzak metastaz gelişimine kadar geçen 
süre olarak hesaplandı. Genel sağkalım süresi ise yine tanı tarihinden vefat zamanına kadar geçen süre veya halen yaşamakta olan hastalarımız için verilerin güncelleştirildiği Aralık 2014 tarihine kadar geçen süre olarak hesaplandı. Hastaların performans skorlarının değerlendirilmesinde Doğu Kooperatif Onkoloji Grubu (ECOG) performans skorlaması kullanıldı. Hastalar kemoterapi almışlar ise kemoterapinin tipi, uygulanan kür sayısı gibi değişkenler değerlendirilmek üzere kaydedildi. Hastalarımızın patoloji kayıtlanı incelenerek tümör boyutu, t evresi, nodal tutulum durumu, vasküler/ lenfatik ve perinöral invazyon durumu, lokalizasyon, tümör evresi vb. parametreler kaydedildi. Ayrıca hastalarımıza ait yaş, cinsiyet gibi demografik veriler belirlendi.

Tüm istatistiksel analizler SPSS 17.0 (SPSS Inc., Chicago, IL, USA) sürümü kullanılarak yapıldı. Tanımlayıcı istatistikler, sürekli değişkenler için \%95 güvenlik aralığında ve ortalama+SE (standart hata oranı) biçiminde ifade edildi. Sağkalım analizi ve eğrisi Kaplan-Meier metodu kullanılarak log-rank testi ile karşlaştırıldı. Tüm p değerleri 2 yönlü olup, $0.05^{\prime}$ in altındaki değerler istatistiksel olarak anlamlı kabul edildi.

\section{Tablo 1. Genel sağkalım üzerine etkili olabilecek faktörler}

\begin{tabular}{|c|c|c|c|c|}
\hline Değişkenler & Sağkalım Yüzdesi & Sağkalım Yüzdesi (\%95 GA) & Log Rank & $\mathbf{P}$ \\
\hline $\begin{array}{l}\text { Cinsiyet } \\
\text { Erkek } \\
\text { Kadın }\end{array}$ & $\begin{array}{l}\% 57 \\
\% 71\end{array}$ & $\begin{array}{c}- \\
116.68(88.1-145.2)\end{array}$ & 2.05 & 0.15 \\
\hline $\begin{array}{l}\text { Tümör çapı } \\
\qquad 5 \mathrm{~cm} \\
<5 \mathrm{~cm}\end{array}$ & $\begin{array}{l}\% 60 \\
\% 67\end{array}$ & $\begin{array}{c}99.4(80.4-118.3) \\
105.1(79.3-130.9)\end{array}$ & 0.04 & 0.84 \\
\hline $\begin{array}{l}\text { Evre } \\
\text { Iyi } \\
\text { Orta } \\
\text { Az }\end{array}$ & $\begin{array}{c}\% 54 \\
\% 64.8 \\
\% 74\end{array}$ & $\begin{array}{c}60.3(42.6-78.1) \\
110.9(89.1-132.7) \\
46.2(32.1-60.4)\end{array}$ & 4.44 & 0.109 \\
\hline $\begin{array}{l}\text { Lenfovasküler invazyon } \\
\text { Var } \\
\text { Yok }\end{array}$ & $\begin{array}{c}\% 34.8 \\
\% 69\end{array}$ & $\begin{array}{c}56.9(42-71.7) \\
119.6(97.2-141.9)\end{array}$ & 4.98 & 0.083 \\
\hline $\begin{array}{l}\text { Perinöral invazyon } \\
\text { Var } \\
\text { Yok }\end{array}$ & $\begin{array}{l}\% 30.6 \\
\% 72.4\end{array}$ & $\begin{array}{c}60.8(38.3-83.3) \\
120.7(96.5-144.9)\end{array}$ & 6.41 & 0.040 \\
\hline $\begin{array}{l}\text { Perforasyon } \\
\text { Var } \\
\text { Yok }\end{array}$ & - & - & 0.94 & 0.33 \\
\hline $\begin{array}{l}\text { Obstrüksiyon } \\
\text { Var } \\
\text { Yok }\end{array}$ & $\begin{array}{l}\% 66.7 \\
\% 63.6\end{array}$ & $\begin{array}{c}83.6(46.8-120.4) \\
112.5(91.2-133.7)\end{array}$ & 0.001 & 0.97 \\
\hline $\begin{array}{l}\text { Tümör yerleşimi } \\
\text { Rektum } \\
\text { Sigmoid } \\
\text { Inen } \\
\text { Çıkan }\end{array}$ & $\begin{array}{c}\% 70 \\
\% 54.1 \\
\% 78.2 \\
\% 62\end{array}$ & $\begin{array}{c}73.3(61.8-84.8) \\
79.8(59.7-99.9) \\
91(54.6-127.4) \\
125.6(99.7-151.4)\end{array}$ & 3.63 & 0.72 \\
\hline $\begin{array}{c}\text { T evresi } \\
\text { T3 } \\
\text { T4 }\end{array}$ & $\begin{array}{l}\% 66.7 \\
\% 46.3\end{array}$ & $\begin{array}{c}114.4(93.2-135.7) \\
43.5(33.5-53.4)\end{array}$ & 11.3 & 0.001 \\
\hline $\begin{array}{l}\text { Lenf nodu sayıs } \\
\qquad \begin{array}{l}<12 \\
>12\end{array}\end{array}$ & $\begin{array}{l}\% 62.6 \\
\% 62.8\end{array}$ & $\begin{array}{l}114.9(85-144.8) \\
89.6(72.4-106.8)\end{array}$ & 0.21 & 0.64 \\
\hline $\begin{array}{l}\text { Histopatoloji } \\
\text { Adenokanser } \\
\text { Müsinöz }\end{array}$ & $\begin{array}{l}\% 98 \\
\% 92\end{array}$ & $\begin{array}{c}109.2(89.1-129.4) \\
49.9(44.1-55.7)\end{array}$ & 0.65 & 0.41 \\
\hline
\end{tabular}




\section{BULGULAR}

Çalışmaya 159 (\%57.4) erkek, 118 (\%42.6) kadın olmak üzere toplam 277 kişi dahil edildi. Hastaların medyan yaşı 60 (aralık 28-89) idi. 277 hastanın medyan sağkalım süresi 21 (aralık 1-184) aydı. Sonuçlar değerlendirildiğinde perinöral invazyon ve tanı anındaki T evresinin genel sağkalım üzerine istatistiksel etkisi olduğu izlendi. 277 hastanın 59'unda perinöral invazyon varken 212 'sinde olmadığı saptandı. Pe- rinöral invazyon olan hastaların 5 yıllık genel sağkalımları \%30.6 iken olmayanların \%72.4 idi (p: 0.04). Tanı anında T 3 olanlarda 5 yıllık genel sağkalım \%66.6 iken, tanı anında T 4 olan hastalarda 5 ylllı genel sağkalımın \%46.3 olduğu görüldü $(\mathrm{p}<0.05)$

Tablo l'de klinikopatolojik faktörlerin genel sağkalım üzerine olan etkileri ve istatistiksel değerleri özetlenmiştir.

\section{Tablo 2. Hastalıksız sağkalım üzerine etkili olabilecek faktörler}

\begin{tabular}{|c|c|c|c|c|}
\hline Değişkenler & Sağkalım Yüzdesi & $\begin{array}{c}\text { Sağkalım Beklentisi Ortalama } \\
\text { (\%95 GA) }\end{array}$ & Log Rank & $\mathbf{P}$ \\
\hline $\begin{array}{l}\text { Cinsiyet } \\
\text { Erkek } \\
\text { Kadın }\end{array}$ & $\begin{array}{l}\% 79.2 \\
\% 72.5\end{array}$ & $\begin{array}{l}112.7(97.0-128.3) \\
93.7(78.9-108.6)\end{array}$ & 0.126 & 0.72 \\
\hline $\begin{array}{l}\text { Tümör çapı } \\
\qquad 5 \mathrm{~cm} \\
<5 \mathrm{~cm}\end{array}$ & $\begin{array}{l}\% 67 \\
\% 60\end{array}$ & $\begin{array}{l}97.7(74.4-121.1) \\
82.5(68.3-96.7)\end{array}$ & 0.84 & 0.35 \\
\hline $\begin{array}{c}\text { Evre } \\
\text { Iyi } \\
\text { Orta } \\
\text { Az }\end{array}$ & $\begin{array}{c}\% 86 \\
\% 75.9 \\
\% 66.7\end{array}$ & $\begin{array}{c}82.5(70.3-94.6) \\
101.2(84.0-118.4) \\
41.0(25.1-56.8)\end{array}$ & 2.46 & 0.29 \\
\hline $\begin{array}{l}\text { Lenfovasküler invazyon } \\
\text { Var } \\
\text { Yok }\end{array}$ & $\begin{array}{l}\% 47.2 \\
\% 82.6\end{array}$ & $\begin{array}{c}44.5(36.4-52.5) \\
107.2(89.3-125.2)\end{array}$ & 29.7 & $<0.001$ \\
\hline $\begin{array}{l}\text { Perinöral invazyon } \\
\text { Var } \\
\text { Yok }\end{array}$ & $\begin{array}{l}\% 50.3 \\
\% 84.4\end{array}$ & $\begin{array}{l}89.4(59.0-119.9) \\
98.7(84.8-112.7)\end{array}$ & 27.68 & $<0.001$ \\
\hline $\begin{array}{l}\text { Perforasyon } \\
\text { Var } \\
\text { Yok }\end{array}$ & - & - & 1.21 & 0.27 \\
\hline $\begin{array}{l}\text { Obstrüksiyon } \\
\text { Var } \\
\text { Yok }\end{array}$ & $\begin{array}{l}\% 21.4 \\
\% 81.3\end{array}$ & $\begin{array}{c}37.5(22.0-53.0) \\
105.2(87.9-122.6)\end{array}$ & 10.71 & 0.001 \\
\hline $\begin{array}{l}\text { Tümör yerleşimi } \\
\text { Rektum } \\
\text { Sigmoid } \\
\text { Inen } \\
\text { Çıkan }\end{array}$ & $\begin{array}{c}\% 80 \\
\% 60 \\
\% 62.5 \\
\% 88.2\end{array}$ & $\begin{array}{l}- \\
- \\
- \\
-\end{array}$ & 13.52 & 0.035 \\
\hline $\begin{array}{c}\text { T evresi } \\
\text { T3 } \\
\text { T4 }\end{array}$ & $\begin{array}{l}\% 78.2 \\
\% 62.1\end{array}$ & $\begin{array}{c}103.7(86.3-121.1) \\
41.6(33.1-50.1)\end{array}$ & 4.74 & 0.029 \\
\hline $\begin{array}{l}\text { Lenf nodu sayısı } \\
\qquad \begin{array}{l}<12 \\
>12\end{array}\end{array}$ & $\begin{array}{l}\% 71.7 \\
\% 80.8\end{array}$ & $\begin{array}{c}95.3(80.1-110.4) \\
101.2(73.6-128.7)\end{array}$ & 0.14 & 0.70 \\
\hline $\begin{array}{l}\text { Histopatoloji } \\
\text { Adenokanser } \\
\text { Müsinöz }\end{array}$ & $\begin{array}{c}\% 92.2 \\
\% 93\end{array}$ & $\begin{array}{c}100.9(83.9-117.9) \\
49.8(43.9-55.8)\end{array}$ & 0.65 & 0.41 \\
\hline
\end{tabular}


Lenfovasküler invazyonun hastalıksız sağkalım üzerine ise istatistiksel olarak anlamlı etkisi olduğu görüldü. LVI mevcut olanlarda sağkalım \%47.2 iken olmayanlarda \%82.6 olduğu görüldü ( $\mathrm{p}<0.001)$. Perinöral invazyon olan hastaların 5 ylllık hastalıksız sağkalımları incelendiğinde de PNI olanlarda $\% 47.2$ olduğu ve olmayanlara (\%82.6) göre belirgin olarak daha az olduğu görüldü $(\mathrm{p}<0.001)$. Tanı sırasındaki T evresinin genel sağkalıma etkisi olduğu gibi progresyonsuz sağkalıma da istatistiksel olarak anlamlı etkisi olduğu gösterilmiştir (p: 0.029). 5 yıllık hastalıksız sağkalım T3 olanlarda \%78.2 iken T4 olanlarda \%62.1 olarak saptand.

5 yıllık hastalıksız sağkalımlar karşılaştırıldığında; rektumda yerleşen tümörlerde 5 ylllık sağkalımın $\% 80$ ve çıkan kolon yerleşimli olanlarda \%88.2 olduğu saptanırken; sigmoid yerleşimli olanlarda \%60 ve inen kolon yerleşimli olanlarda \%62.5 olduğu bulundu ve rektum ve çıkan kolon yerleşimli tümörü olanlarda 5 yıllık hastalıksız sağkalımın belirgin olarak daha iyi olduğu görüldü (p: 0.035). Obstrüksiyonu olmayan 268 hasta ve obstrüksiyon bulunan 9 hastada, hastalıksız sağkalımlar sırası ile \%81.3 ve \%21.4 idi ve istatistiksel olarak anlamlı farklılık mevcut idi (p: 0.001). Tablo 2'de klinikopatolojik faktörlerin hastalıksız sağkalım üzerindeki etkileri özetlenmiştir.

\section{TARTISSMA}

Kolorektal kanserler tüm dünyada ve ülkemizde sindirim sistemi kanserlerinin başını çekmektedir. Günümüzde tüm gelişmelere rağmen kolorektal kanser tanısı konulan hastaların halen \%60 kadarı ilk 5 yıl içinde hayatını kaybetmektedir. Ancak erken tanı ve tedavi metodları ile 5 yıllık sağkalım seviyeleri \%90'lara kadar ulaşabilmektedir. Yapılan çalışmalarda kolorektal kanser sıklığının 40 yaş ve üzerinde belirgin olarak arttığı gösterilmiştir (2). Çalışmamızda da buna benzer olarak medyan yaşın 60+12.8 (3-4) olduğu görüldü.

Burton ve ark. yaptığı çalışmada sağ ve sol kolon yerleşimli olanlar arasında 4 yıllık sağkalım açısından belirgin farklılık olmadığı gösterilmiştir (5). Quah ve ark. tarafından evre II kolon kanserli hastalarda yapılan çalışmada tümör yerleşim yerinin 5 yıllık sağkalımla ilişkisiz olduğu saptanmıştır (6). Kolorektal kanserlerin büyük kısmı adenokanser tipinde, yaklaşı \%20'si müsinöz tipte ve \%1'lik kısım ise onun bir alt tipi olan taşlı yüzük hücreli karsinom histolojik tipindedir $(7,8)$. Chen ve ark.'nın yaptığı çalışmada taşlı yüzük hücreli ve müsinöz tipin adenokansere göre daha kötü prognozlu olduğu gösterilmiştir (8). Tümör çapı artışı ile sağkahım arasında ters orantı olduğunu gösteren çalışmalar bulunmakla beraber $(9,10)$, Quah ve ark.'larının yaptığı evre II kolon tümörlü hastaların dahil edildiği çalışmada aynı ilişki gös- terilememiştir (6). Kolorektal kanserlerde tutulan lenf nodu sayısının sağkalım üzerine etkili olduğu kadar nüks gelişme riskiyle de doğru orantılı olduğu düşünülmektedir $(11,12)$. Hastalı̆ı̆ grade'i ile sağkalım arasında önemli ilişki olduğu düşünülmektedir $(7,13)$. Cohen ve ark.'ları tarafınca yapılmış olan çalışmada tümör evresinin sağkalım üzerine bağımsız bir prognostik faktör olduğu saptanmıştır (14). Çalışmamızda tümör çapı, histopatolojik tip ve evrenin sağkalıma olumsuz etkisi gösterilememiştir.

Kolon kanserli hastalar klinikte birçok semptom ile acile başvurabilmekle beraber başlıca önemli iki semptom obstrüksiyon ve perforasyondur. Obstrüksiyon ve perforasyon bulguları ile gelen hastaların pronozunun ise daha kötü olduğu belirtilmektedir. Peterson ve ark.'larının Dukes B hastalarda yaptığı çalışmada obstrüksiyon ve perforasyon bağımsız bir risk faktörü olarak bulunmuştur (15). Rault ve ark.'ları tarafinca yapılan bir diğer çalışmada ise operasyon öncesi obstrüksiyon mevcut olan hastalarda sağkalımın daha az olduğu görülmüştür (16). Lenfovasküler invazyon ve perinöral invazyon varlığı kolon kanserlerinde önemli prognostik belirteçlerdir. Quah ve ark.'ları tarafınca evre II hastalarda yapılmış olan çalışmada sağkalım üzerine etkili bulunmuştur (6). TNM evreleme sisteminin temel unsurlarindan biri olan T evresinin bağımsız bir prognostik faktör olduğu kabul edilmektedir. Hermanek ve ark.'larının yapmış olduğu çalışmada T evresinin sağkalımı etkileyen bağımsız bir faktör olduğu kanıtlanmıştır (17).

Bizim çalışmamızda ise perinöral invazyon mevcudiyeti ve tanı anındaki T evresinin yüksekliğinin genel sağkalım üzerine; lenfovasküler invazyon ve perinöral invazyon varlığı, T evresi yüksekliğinin ve obstrüksiyon varlığının hastalıksız sağkalım üzerine olumsuz etkisi olduğu izlenirken, rektum yerleşimli tümörlerin prognozunun daha iyi olduğu görülmüştür.

Hasta gruplarında baktı̆̆ımız istatistiksel olarak anlamlı fark bulunmayan parametrelerin numerik olarak prognoz üzerine etkisi olduğu görülmektedir. Çalışmamızdaki vaka sayısının azlığının ve takip sürelerinin kısalığının parametrelerin istatistiksel anlamlı farka ulaşmasını engellediği kanaatindeyiz. Geniş vaka sayısı ve daha uzun takip süreleri baz alınarak histopatolojik bulgular ile toplam sağkalım arasındaki ilişkinin daha net değerlendirilebileceğini ve bu bilgiler ışı̆̆ında prognozun vakalar bazında daha iyi belirlenerek en uygun tedavi stratejisinin uygulanabileceğini düşünmekteyiz.

\footnotetext{
'Tüm yazarlar herhangi bir çıkar çatışması olmadığını kabul ederler."
} 


\section{KAYNAKLAR}

1. Siegel RL, Miller KD, Jemal A. Cancer statistics, 2015. CA Cancer J Clin 2015;65:5-29.

2. Eddy DM. Screening for colorectal cancer. Ann Intern Med 1990;113:373-84.

3. Levin B, Lieberman DA, McFarland B, et al. Screening and surveillance for the early detection of colorectal cancer and adenomatous polyps, 2008: a joint guideline from the American Cancer Society, the US Multi-Society Task Force on Colorectal Cancer, and the American College of Radiology. Gastroenterology 2008;134:1570-95.

4. Stapley S, Peters TJ, Sharp D, Hamilton W. The mortality of colorectal cancer in relation to the initial symptom at presentation to primary care and to the duration of symptoms: a cohort study using medical records. Br J Cancer 2006; 95:1321-5.

5. Burton S, Norman AR, Brown G, et al. Predictive poor prognostic factors in colonic carcinoma. Surg Oncol 2006;5:71-8.

6. Enker WE, Havenga K, Polyak T, et al Abdominoperineal resection via total mesorectal excision and autonomic nerve preservation for low rectal cancer. World J Surg 1997;21:715-20.

7. Küpelioğlu AA. Kolorektal kanserde histopatoloji. Turkiye Klinikleri J Surgery 2004;9:25-7.

8. Chen JS, Hsieh PS, Chiang JM, et al. Clinical outcome of signet ring cell carcinoma and mucinous adenocarcinoma of the colon. Chang Gung Med J 2010;33:51-7.
9. Rosai J. Ackerman's Surgical Pathology: Gastrointestinal Tract. 8th. Ed. St. Louis: The CV Mosby Company, 1996;589-800.

10. Wiggers T, Arends JW, Schutte B, et al. A multivariate analysis of pathologic indicators in large bowel cancer. Cancer 1988;61:386-95.

11. Read TE, Mutch MG, Chang BW, et al. Locoregional recurrence and survival after curative resection of adenocarcinoma of the colon. J Am Coll Surg 2002;195:33-40

12. Radespiel-Tröger M, Hohenberger W, Reingruber B. Improved prediction of recurrence after curative resection of colon carcinoma using tree-based risk stratification. Cancer 2004;100:958-67.

13. Sökmen S. Kolorektal kanserde prognoz, kolorektal özel sayısı. Türkiye Klinikleri Journal of Surgery 2004;9:57-65.

14. Cohen AM, Tremittera S, Candela F, et al. Prognosis of node - positive colon cancer. Cancer 1991;67:1859-61.

15. Petersen VC, Baxter KJ, Love SB, Shepherd NA. Identification of objective pathological prognosis determinants and models of prognosis in Dukes` B colon cancer. Gut 2002;51:65-9.

16. Rault A, Collet D, Sa Cunha A, et al. Surgical management of obstructed colonic cancer. Ann Chirr 2005;130:331-5.

17. Newland RC, Dent OF, Lyttle MN, et al. Pathologic determinants of survival associated with colorectal cancer with lymph node metastases. A multivariate analysis of 579 patients. Cancer 1994;73:2076-82. 